\title{
Aspectos Relevantes da Interface Entre Diabetes Mellitus e Infeç̧̃̃o
}

\section{RESUMO}

O diabetes mellitus (DM) é uma doença de alta prevalência nas sociedades modernas, na maioria das vezes com tratamento inadequado ou ausente. Apesar de geralmente considerado como fator de risco independente para ocorrência e gravidade de infecções em geral, o DM não apresenta evidência clínica forte de sua relação com infecção. Observase, porém, uma maior ocorrência de certas infecções em pacientes com DM, com curso menos favorável para algumas delas. Há também tipos de infecção quase exclusivos de pacientes com DM. Experimentalmente, observa-se depressão da atividade dos neutrófilos, menor eficiência da imunidade celular, alteração dos sistemas antioxidantes e menor produção de interleucinas. Com relação às infecções comuns, as que envolvem o trato respiratório não tếm comprovadamente maior gravidade em pacientes com DM, exceção feita ao pneumococo - por isso a recomendação para sua vacinação contra S. pneumoniae e influenza. Quanto ao trato urinário, há maior ocorrência de bacteriúria assintomática em mulheres com DM, com maiores índices de pielonefrite, necrose papilar, abscesso perinéfrico, pielonefrite xantogranulomatosa, e cistite e pielonefrite gangrenosas. Periodontite e infecções de partes moles são também mais comuns no DM. Cada tipo de infecção é associado a germes típicos, e seu conhecimento é fundamental para um tratamento inicial adequado. As infecções quase exclusivas de pacientes com DM incluem otite externa maligna, mucormicose rinocerebral, colecistite gangrenosa e o somatório de alterações que caracterizam o pé diabético. $\bigcirc$ conhecimento destas infecções assume maior importância por requererem freqüentemente uma abordagem multidisciplinar, envolvendo endocrinologistas, infectologistas, cirurgiões vasculares e nefrologistas, dentre outros. (Arq Bras Endocrinol Metab 2002;46/3:221-229)

Descritores: Diabetes mellitus; Infecção; Antibióticos; Pé diabético; Infecções do trato urinário; Infecções de partes moles

\section{artigo original}

\author{
Jaime L.L. Rocha \\ Hugo C.C. Baggio \\ Clóvis A. da Cunba \\ Edgard A. Niclewicz \\ Silmara A.O. Leite \\ Maria I.D.K. Baptista
}

Serviços de Endocrinologia, Clínica Médica e Infectologia do Hospital Nossa Senhora das Graças, Curitiba, PR.

\begin{abstract}
Relevant Issues in the Interaction Between Diabetes Mellitus and Infection. Diabetes mellitus (DM) is a highly prevalent disease in modern societies, most of the times being either inappropriately treated or not treated at all. Though generally considered to be an independent risk factor for the occurrence and severity of infections in general, DM has not been clinically proven to have any strong association with infection. There are, however, certain infections that are more common in DM, sometimes with a less favorable course than in non-diabetics. Other types of infection affect almost exclusively patients with DM. Experimentally, DM patients have a depressed neutrophil activity, a less effective cell mediated immunity, altered antioxidant systems and diminished interleukin synthesis. Regarding common infections, those affecting the respiratory tract have not been proven to be more serious in DM patients, with the exception of S. pneumoniae infections - thus the recommendation to vaccinate them against pneumococcus and influenza. As for urinary tract infections, bacteriuria takes place more commonly in women with DM, more frequently complicated by pyelonephritis, papillary necrosis, xanthogranulomatous pyelonephritis and gangrenous cystitis/ pyelonephritis. Periodontitis and soft-tissue infections are also more common
\end{abstract}

Recebido em 02/10/01

Revisado em 18/02/02 Aceito em 08/03/02 
in DM. Each specific infection is associated with typical microbes, and their knowledge is essential for an appropriate initial treatment. The nearly exclusively DM-related infections include malignant external otitis, rhinocerebral mucormycosis, gangrenous cholecystitis, and the sum of alterations referred to as "diabetic foot". The general knowledge of these infections assumes great importance since they often require a multidisciplinary approach, involving endocrinologists, infectologists, nephrologists and vascular surgeons, among others. (Arq Bras Endocrinol Metab 2002;46/3:221-229)

Keywords: Diabetes mellitus; Infection; Diabetic foot; Urinary tract infections; Antibiotics; Soft tissue infections

$\mathrm{O}$ Diabetes Mellitus (DM) é uma doença muito prevalente nas sociedades modernas, cabendo principalmente ao endocrinologista e ao clínico geral o seu diagnóstico e correto manejo. Vale lembrar que o DM acomete cerca de 7,6\% da população brasileira entre 30 e 69 anos de idade. Aproximadamente metade dos pacientes desconhece o diagnóstico e $1 / 4$ dos reconhecidamente portadores de $\mathrm{DM}$ não faz qualquer tipo de tratamento (1).

Considerando-se a sua alta prevalência e descaso, os médicos devem estar preparados não apenas para lidar com as intercorrências mais simples e cotidianas da doença, mas também com as mais graves, como algumas infecções. Este assunto é constante ponto de debate e pesquisa (2).

Ao contrário do que se pensa, não são fortes as evidências clínicas que sustentam a associação entre DM e infecção (3). O que está bem definido é uma maior incidência de infecções específicas, muitas vezes com maiores taxas de complicações e maior severidade. Além disso, há também alguns quadros infecciosos quase exclusivos do diabético.

A outra face desta situação que não pode deixar de ser mencionada são as freqüentes descompensações do próprio DM (como cetoacidose e coma hiperosmolar) frente aos quadros infecciosos.

\section{ALTERAÇÕES IMUNOLÓGICAS}

Diversos achados laboratoriais nos ajudam a compreender essa "parceria" entre DM e infecção (4-6). Sabe-se que o paciente diabético apresenta:

1) depressão da atividade dos polimorfonucleares neutrófilos, diretamente relacionada aos níveis de hiperglicemia (principalmente na presença de acidose). Os neutrófilos apresentam-se com menor capacidade de fagocitose;
2) alteração na aderência, quimiotaxia e opsonização leucocitária. O sistema imune celular apresenta uma resposta ineficiente e retardada aos agentes nocivos;

3) alteração dos sistemas antioxidantes e menor produção de interleucinas (IL-2), pontos-chave no processo inflamatório necessário a uma resposta imunológica eficaz.

A função humoral, por outro lado, parece estar preservada, o que pode ser comprovado pela resposta adequada que existe à vacina antipneumocócica, por exemplo.

É sempre muito difícil estabelecer e documentar um vínculo direto, em estudos clínicos, entre um bom controle glicêmico e uma melhor resposta imunológica. Isso se deve à existência de muitos outros fatores implicados na gênese de quadros infecciosos (7).

\section{INFECÇÕES COMUNS}

Trato respiratório. Não está bem definido se DM é um fator de risco independente na incidência e severidade destas infecções. Em um dos maiores estudos sobre pneumonias adquiridas na comunidade, estabeleceu-se um odds ratio de 1,3 para morte em diabéticos (8). Entretanto, esta associação não foi confirmada em outros estudos. O que se evidencia é uma maior incidência de certos microorganismos em DM, como Staphylococcus aureus, bacilos Gram-negativos (BGN) e Mycobacterium tuberculosis. Em estudos da primeira metade do século XX, a tuberculose se apresentava 34 vezes mais incidente em diabéticos (9).

Apesar da falta de evidências semelhantes na literatura, a experiência ainda não publicada do nosso serviço tem mostrado que, no caso das pneumonias por BGN, muitas vezes ocorre uma rápida e progressiva lesão pulmonar, levando muitos doentes ao óbito em curto espaço de tempo.

Uma vez estabelecido maior risco para bacteremia e maior mortalidade por pneumonia pneumocócica, o American College of Physicians recomenda que todos os pacientes diabéticos recebam vacinas contra pneumococo e influenza $(10,11)$.

Trato urinário. São vários os estudos que demonstram uma maior taxa de bacteriúria assintomática (BA) em mulheres diabéticas ( 2 a 4 vezes mais freqüente do que em não-diabéticas) $(2,12,13)$. Para fins de estudo, define-se uma paciente como portadora de BA quando ela apresenta duas ou mais uro- 
culturas positivas com um mesmo germe, com contagem de colônias maior ou igual a $10^{5} \mathrm{ufc} / \mathrm{ml}$, obtidas a partir do jato urinário intermediário, na ausência de qualquer sintoma urinário (14). Na prática, uma urocultura positiva é o suficiente.

A maioria dos estudos que associam DM e BA foi realizada antes da década de 70 , e não deixa claro um motivo para esta associação (14-16). Glicosúria, qualidade do controle glicêmico e duração do DM não parecem ser fatores importantes $(12-14,17)$. Por sua vez, a presença de neuropatia diabética com bexiga neurogênica é apontada como o principal fator de risco para desenvolvimento de bacteriúria e infecção devido à urina residual (17). Postula-se ainda um papel às alterações leucocitárias e a uma maior facilidade de adesão bacteriana ao epitélio vesical (14).

O papel de outros fatores, como instrumentações freqüentes e a existência de nefropatia, não parece estar bem estabelecido $(13,14,17)$. Observa-se que pacientes com doença vascular diabética avançada, na forma de retinopatia, cardiopatia ou doença vascular periférica, têm também maiores taxas de bacteriúria $(13,14,17,18)$. O mais provável é que a maior freqüência de colonização urinária em pacientes diabéticas seja resultado do somatório destas alterações, e não conseqüência de um único fator isolado.

Um estudo publicado por Geerlings e cols. (12) encontrou uma prevalência de bacteriúria assintomática de $26 \%$ em mulheres diabéticas contra $6 \%$ em mulheres não-diabéticas. Interessantemente, as taxas de BA em homens não parecem ser afetadas pela presença de $\operatorname{DM}(13,14,18)$.

De acordo com um estudo publicado por Hooton e cols. (19), 8\% das mulheres desenvolvem sintomas até 1 semana após detecção de bacteriúria assintomática, sendo esta o principal fator de risco para infecção do trato urinário (ITU) em mulheres com DM tipo 2 (20). Nos casos em que já se desenvolveu ITU, o quadro clínico é semelhante entre pacientes diabéticos e não-diabéticos, exceto pelo fato bem documentado de um acometimento do trato urinário superior em até $80 \%$ das ITU naqueles com DM $(13,14,17)$. Além disso, há uma maior incidência de bilateralidade nos casos de pielonefrite e uma maior taxa de complicações nestes pacientes (13). Também se percebe uma maior taxa de infecções fúngicas, especialmente por espécies de Candida (2).

Entre as principais complicações se destacam a necrose papilar, cujo diagnóstico é estabelecido pela pielografia retrógrada; abscesso renal ou perinéfrico; pielonefrite xantogranulomatosa, e cistite e pielonefrite gangrenosas. Cerca de $1 / 3$ dos abscessos pe- rinéfricos ocorrem em diabéticos $(13,21)$, devendo o médico suspeitar deste diagnóstico, bem como da possibilidade de pielonefrite gangrenosa, quando houver persistência da febre por mais de quatro dias após o início do tratamento com o antibiótico adequado (baseado em antibiograma).

Um campo ainda aberto para muitas pesquisas é o tratamento da bacteriúria assintomática em DM. Será que devemos fazer exames de rotina? Devemos tratar? Qual é a melhor forma de tratamento? Por enquanto não se realizaram estudos clínicos de dimensões suficientemente grandes para responder a estas questões. Devido ao maior risco de complicações potencialmente graves decorrentes de infecções do trato urinário alto, muitas autoridades recomendam que se realize antibioticoterapia para pacientes diabéticas com BA $(13,18)$, e essa é a conduta adotada pelo nosso serviço. Pela alta prevalência de acometimento do parênquima renal, advoga-se a terapia por 7 a 14 dias (13). Mesmo com tratamento, $70 \%$ dos pacientes têm recorrência da bacteriúria em até 34 meses (13), em 75\% dos casos por novos germes $(13,14)$. Pacientes com alterações estruturais como cistocele, retocele ou urina residual devem ser tratadas apenas se desenvolverem sintomas $(13,17)$.

Periodontite. Esta infecção ocorre com grande freqüência em pacientes com DM, sendo até 4 vezes mais comum nestes pacientes do que na população geral (22). Caracterizada por infecção bacteriana crônica das estruturas periodontais, tem como possível complicação a perda do dente afetado. Os pacientes diabéticos têm mais freqüentemente doença agressiva do que os não-diabéticos (23). O risco parece ser semelhante entre diabéticos com bom controle glicêmico e não-diabéticos, e é maior em pacientes com DM de longa duração (24).

De especial interesse médico é a comprovação de que a periodontite favorece uma piora nos níveis glicêmicos nos diabéticos $(22,23,25)$. É recomendável, portanto, estar sempre alerta aos sinais desta infecção ao examinar um paciente com DM.

Infecções de partes moles. As infecções envolvendo os pés são as mais freqüentes em pacientes diabéticos (2). Além destas, abscessos, celulites, erisipelas, fasceíte necrotizante e piomiosite também ocorrem mais comumente no diabetes $(26,27)$. Sinert e cols. recomendam screening para DM em todos os pacientes com infecções de partes moles devido à sua alta prevalência nesta subpopulação (26).

A fasceíte necrotizante é a mais importante delas devido ao risco de rápida evolução para sepse, 
até falência de múltiplos órgãos e sistemas $(2,27)$. Deve ser suspeitada sempre que o paciente se apresentar com febre e dor local intensa, geralmente com poucos sinais inflamatórios na pele suprajacente, acompanhado por sinais de toxicidade sistêmica $(2,27,28)$. Na maioria das vezes ocorre formação de gás, palpável em cerca de $50 \%$ dos casos mas melhor identificada através da radiografia simples (2). Para se fazer o diagnóstico definitivo é necessário demonstrar uma reduzida resistência da fáscia à dissecção romba durante a exploração cirúrgica $(27,28)$. Os locais mais afetados são as extremidades, períneo e parede abdominal, mas pode acometer qualquer parte do corpo $(27,28)$. No diabetes esta infecção é tipicamente polimicrobiana, contando com um germe anaeróbio e um ou mais aeróbios $(2,28)$. O tratamento exige início precoce de antimicrobianos e debridamento cirúrgico agressivo, além de medidas suportivas e, eventualmente, oxigênio hiperbárico $(2,27,28)$. Devido à baixa velocidade de multiplicação do estreptococo na fasceíte, a penicilina isolada é pouco efetiva. Recomenda-se esquema associado com clindamicina (com ou sem adição de aminoglicosídeos, de acordo com o resultado das culturas) $(2,27,28)$.

A gangrena de Fournier é um tipo específico de fasceíte necrotizante que ocorre na genitália masculina (2). Exige um alto grau de suspeição devido à escassez de achados ectoscópicos precoces. Não há evidências contundentes de sua maior freqüência em pacientes com DM (28).

Outra infecção comprovadamente mais freqüente em diabéticos é a piomiosite $(28,29)$, uma infecção purulenta primária da musculatura estriada esquelética, acompanhada freqüentemente por um ou mais abscessos intramusculares (29). Tem ocorrência comum em países tropicais, mas é rara em outras regiões (29). O Staphylococcus aureus é o agente causador na maioria dos casos (30). Inicialmente, o paciente se apresenta com dor leve, edema e induração local, com ou sem febre. Cerca de 10 a 21 dias após, a dor já é mais intensa, o paciente se encontra febril, e à punção já se pode obter secreção purulenta. Após esta fase se iniciam as manifestações de sepse, e a lesão inicial se torna extremamente dolorosa e eritematosa (30). O tratamento consiste na drenagem cirúrgica de todos os abscessos e antibioticoterapia sistêmica com penicilinas resistentes à penicilinase (como a oxacilina), ou cefalosporinas de primeira geração (e.g., cefazolina). Persistência da febre após início de antimicrobianos baseados em antibiograma devem levantar a suspeita de persistência de abscesso não drenado (30).

\section{INFECÇÕES “EXCLUSIVAS” DO DM}

Diversas infecções são peculiares ou muito mais prevalentes nos pacientes com DM (tabela 1). Dentre as principais, devemos fazer algumas considerações sobre as seguintes:

Otite Externa Invasiva ("Maligna"). A otite externa maligna (OEM) tornou-se muito menos comum nas últimas décadas, porém permanece uma complicação com alta morbidade e potencialmente fatal (31). A menor incidência deve-se principalmente ao melhor controle metabólico dos pacientes diabéticos. Esta doença acomete principalmente pacientes idosos com DM (mais de 90\% dos pacientes com OEM apresentam alguma forma de intolerância à glicose) (32). O agente causador é a Pseudomonas aeruginosa em mais de $95 \%$ dos casos (32).

Com relação ao seu diagnóstico, é imprescindível que, na presença de otalgia constante, otorréia e perda auditiva sem febre, seja aventada a possibilidade de OEM. A dor é geralmente intensa, não responsiva às medicações tópicas usadas na otite externa aguda. Com a progressão da infecção e ocorrência de osteomielite da base do crânio, pode ocorrer comprometimento de nervos cranianos, em especial do sétimo par (ocorre paralisia facial em até $50 \%$ dos casos) $(32,33)$. Este achado é sugestivo de um pior prognóstico $(32,33)$. Outros nervos, como glossofaríngeo, vago e hipoglosso podem ser afetados nos seus forames correspondentes. O acometimento do nervo abducente e do trigêmeo ocorre raramente; neurite óptica foi relatada (34). Os nervos olfatório, oculomotor e troclear aparentemente são poupados $(32,33)$.

Apesar de ser inespecífica, uma velocidade de hemossedimentação bastante elevada é o achado laboratorial mais característico da OEM (32). O "padrão ouro" para diagnóstico parece ser a ressonância nuclear magnética (RNM) com gadolínio.

$O$ tratamento se baseia na antibioticoterapia sistêmica prolongada (4-6 semanas), não havendo utilidade no uso de antimicrobianos tópicos (tabela 1 ). O paciente deve ser acompanhado de perto por especialistas da área otorrinolaringológica.

Mucormicose rinocerebral. Diferentes espécies de Rhizopus, Rhizomucor e Cunninghamella são os principais responsáveis por esta infecção (menos comumente outras espécies podem estar associadas Mucor, Absidia etc.). Esta entidade incomum acomete apenas indivíduos com alguma doença de base grave, sendo que $50 \%$ dos casos ocorrem em DM, principalmente na vigência de cetoacidose (35). 
Tabela 1. Tratamento das infecções tipicamente associadas ao DM.

\begin{tabular}{|c|c|c|c|}
\hline Infecção & Clínica & Tratamento & Observações \\
\hline $\begin{array}{l}\text { Abscesso } \\
\text { perinéfrico }\end{array}$ & $\begin{array}{l}\text { Febre após } 4 \text { dias } \\
\text { de ATB, dor à } \\
\text { manobra de Gior- } \\
\text { dano }\end{array}$ & $\begin{array}{l}\text { 1. Associado com estafilococcia } \\
\text { - Oxacilina } 2 \mathrm{~g} \text { EV q4h; ou } \\
\text { - Cefazolina } 2 \mathrm{~g} \text { EV q8h; ou } \\
\text { - Vancomicina } 15 \mathrm{mg} / \mathrm{Kg} \text { EV q6h (alergia a penicilina) } \\
\text { 2. Associado com pielonefrite } \\
\text { - FQ (Ciprofloxacina } 400 \mathrm{mg} \text { EV q12h); ou } \\
\text { - Ceftriaxona } 2 \mathrm{~g} / \mathrm{d} \text {; ou } \\
\text { - Piperacilina/tazobactam 4,5g EV q8h }\end{array}$ & $\begin{array}{l}\text { Geralmente é necessária } \\
\text { drenagem cirúrgica ou per- } \\
\text { cutânea } \\
\text { Afastar fatores obstrutivos }\end{array}$ \\
\hline $\begin{array}{l}\text { Pielonefrite } \\
\text { enfisematosa }\end{array}$ & $\begin{array}{l}\text { Febre após } 4 \text { dias } \\
\text { de ATB, Giordano + }\end{array}$ & $\begin{array}{l}\text { 1. FQ (Ciprofloxacina } 400 \mathrm{mg} \text { EV q12h) + Metronidazol } \\
\text { 7,5mg/kg EV q6h; ou } \\
\text { 2. Ceftriaxona } 2 \mathrm{~g} / \mathrm{d} \text {; ou } \\
\text { 3. Piperacilina/tazobactam 4,5g EV q8h; ou } \\
\text { 4. Carbapenêmicos (Imipenem/cilastatina } 0,5 \mathrm{~g} \text { EV q6h } \\
\text { ou Meropenem } 1 \mathrm{~g} \text { EV q8h) }\end{array}$ & $\begin{array}{l}\text { Intervir cirurgicamente o } \\
\text { quanto antes } \\
\text { Muitas vezes necessita de } \\
\text { nefrectomia de urgência }\end{array}$ \\
\hline OEM & $\begin{array}{l}\text { Otalgia, otorréia, } \\
\text { hipoacusia e } \\
\text { celulite }\end{array}$ & $\begin{array}{l}\text { 1. Ceftazidima, } 2 \mathrm{~g} \text { EV q8h; ou } \\
\text { 2. FQ (Ciprofloxacina } 400 \mathrm{mg} \text { EV q12h) + Ácido acético } \\
\text { tópico; ou } \\
\text { 3. Cefalosporinas de } 4^{a} \text { geração (Cefepime 1-2g EV } \\
\text { q12h); ou } \\
\text { 4. Carbapenêmico (Imipenem/cilastatina 0,5g EV q6h } \\
\text { ou Meropenem } 1 \mathrm{~g} \text { EV q8h) }\end{array}$ & $\begin{array}{l}\text { Avaliação otorrinolaringológi- } \\
\text { ca imediata } \\
\text { Debridamento cirúrgico }\end{array}$ \\
\hline $\begin{array}{l}\text { Mucormicose } \\
\text { rinocerebral }\end{array}$ & $\begin{array}{l}\text { Dor facial ou ocu- } \\
\text { lar, febre, letargia } \\
\text { e lesões nasais } \\
\text { enegrecidas }\end{array}$ & Anfotericina B 1,0-1,5mg/Kg EV ao dia. Dose total 2,5-3,0g. & $\begin{array}{l}\text { Cirurgia de emergência } \\
\text { (repetida sempre que houver } \\
\text { necrose) } \\
\text { Alta associação com } \\
\text { cetoacidose }\end{array}$ \\
\hline $\begin{array}{l}\text { Colecistite } \\
\text { enfisematosa }\end{array}$ & $\begin{array}{l}\text { Semelhante a } \\
\text { colecistite aguda }\end{array}$ & $\begin{array}{l}\text { 1. Ceftriaxona } 2 \mathrm{~g} / \mathrm{d}+\text { Metronidazol } 7,5 \mathrm{mg} / \mathrm{kg} \text { EV q6h; ou } \\
\text { 2. Ampicilina/sulbactam, } 3 \mathrm{~g} \text { EV q6h; ou } \\
\text { 3. Ampicilina } 2 \mathrm{~g} \text { EV } 6 / 6 \mathrm{~h},+ \text { Gentamicina } 5 \mathrm{mg} / \mathrm{Kg} \text { dose } \\
\text { única diária + Metronidazol 7,5mg/kg q6h; ou } \\
\text { 4. Carbapenêmico: Imipenem/cilastatina } 0,5 \mathrm{~g} \text { EV q6h } \\
\text { ou Meropenem } 1 \mathrm{~g} \mathrm{EV} \mathrm{q8h).}\end{array}$ & $\begin{array}{l}\text { Colecistectomia de } \\
\text { emergência } \\
\text { Alta mortalidade }\end{array}$ \\
\hline
\end{tabular}

ATB: antibiótico; FQ: fluoroquinolonas; OEM: otite externa maligna; EV: endovenoso; VO: via oral.

Obs.: Ajustar a dose conforme a função renal e hepática do paciente; passar para ATB VO assim que o quadro apresentar melhora; sempre basear a escolha do ATB nos conhecimentos da flora local e principalmente no antibiograma.

As manifestações clínicas iniciais se caracterizam por um quadro de sinusite, com dor facial ou ocular e obstrução nasal, com ou sem secreção purulenta. Nesta fase já podem ser encontradas lesões necróticas enegrecidas nas conchas nasais. A evolução do quadro é rápida, com disseminação a partir dos seios paranasais às estruturas adjacentes, como palato, órbita e cérebro, surgindo muitas vezes a tríade clássica: proptose unilateral com celulite, sinusite paranasal e oftalmoplegia com cegueira.

A confirmação diagnóstica deve ser imediata, com cultura e biópsia, pois a mortalidade ultrapassa $50 \%$. Os principais fatores associados à mortalidade são o diagnóstico tardio, presença de hemiparesia ou hemiplegia, doença sinusal bilateral, doença renal, leucemia e uso prévio de desferroxamina (36).

O tratamento é sempre muito difícil e prolongado, consistindo de uma abordagem multidisciplinar entre cirurgia de cabeça e pescoço, infectologia e endocrinologia (tabela 1 ).

Colecistite gangrenosa (enfisematosa). A colecistite gangrenosa é uma infecção intra-abdominal grave e incomum, caracterizada pela formação de gás dentro da vesícula biliar, com uma maior taxa de mortalidade quando comparada aos quadros de colecistite aguda em pacientes não-diabéticos ( $15 \%$ contra 1 a $4 \%$ ).

Cerca de $1 / 3$ dos casos ocorre em DM e em mais da metade das vezes não se detecta a presença de cálculos. Nestes casos não estão sempre presentes sinais de irritação peritoneal, mas pode haver crepitação durante a palpação abdominal, um sinal patognomônico (37). Nestes casos se deve suspeitar da presença de enterobactérias e germes anaeróbios.

É fundamental um rápido diagnóstico para que se proceda com colecistectomia de emergência e antibioticoterapia de amplo espectro (tabela 1 ). 
Pielonefrite gangrenosa (enfisematosa). Uma possível e cada vez menos freqüente complicação das ITU é a formação de gás no parênquima renal, tecido perinéfrico ou sistema coletor urinário, denominada de pielonefrite gangrenosa. Setenta a $90 \%$ ou mais dos casos ocorrem em DM $(13,37)$. A necrose papilar complica cerca de $20 \%$ casos (37).

Os principais agentes etiológicos são a Escherichia coli (50-75\% dos casos) e/ou anaeróbios. Muitas vezes o paciente acaba necessitando de nefrectomia total para resolver esta complicação (37).

O diagnóstico baseia-se principalmente na suspeita clínica (persistência da febre após 4 dias de antibioticoterapia adequada) e na tomografia abdominal. Apesar de a radiografia simples demonstrar a presença de ar em menos de $1 / 3$ dos casos de pielonefrite gangrenosa, alguns autores recomendam a sua realização em todos os pacientes diabéticos com pielonefrite devido à gravidade dessa infecção $(13,17)$.

Pé diabético (tabela 2). Infecções acometendo os pés são as principais infecções de partes moles em diabéticos (2). Além disso, são também a principal causa de amputação acarretando altos custos à sociedade. É importante citar que amputações não traumáticas ocorrem 100 vezes mais freqüentemente em pacientes diabéticos (38).

Cerca de $51 \%$ dos pacientes internados em enfermarias endocrinológicas de hospitais universitários apresentam alguma forma de pé diabético. $\mathrm{O}$ Hospital de Clínicas de Porto Alegre relatou um gasto aproximado do equivalente a cerca de 4.100 dólares para 21 dias de tratamento de úlceras em pé diabético.
O Centro de Pé Diabético da Fundação Hospitalar do Distrito Federal apresentava em 1999 um gasto trimestral do equivalente a 18.450 dólares apenas com distribuição ambulatorial de antimicrobianos $(39,40)$.

Os principais fatores de risco para o desenvolvimento de úlceras nos pés são a neuropatia diabética periférica (diminuição da sensibilidade), desinformação, doença vascular periférica, história de úlceras prévias e dermatoses comuns (40).

É consenso geral entre endocrinologistas e infectologistas que a principal medida no tratamento do pé diabético é a detecção precoce, alcançando-se mais de $90 \%$ de sucesso para as úlceras que recebem manejo adequado, incluindo alívio da pressão local, tratamento das infecções e revascularização quando indicada (41). Uma causa comum de falha no tratamento é o constante apoio de peso sobre a lesão. Para evitar este problema, há diversas formas de palmilhas anatômicas, sapatos especiais e imobilizações (e.g., bota gessada, Scotchcast boot, imobilização de Caville) (41). Outro ponto importante é o adequado debridamento de calosidades, pois estas aumentam em até $30 \%$ a pressão exercida sobre determinado ponto. Ainda com relação às medidas preventivas é imprescindível um adequado controle glicêmico para que se possa evitar o principal fator predisponente das lesões no pé diabético que é a neuropatia periférica.

Ao contrário do que se poderia pensar, o diagnóstico de infecção na presença de uma úlcera nem sempre é uma tarefa fácil. Isto se deve ao fato de febre, leucocitose e calafrios poderem estar ausentes em até $2 / 3$ dos casos. Além disso, o médico deve estar atento também a detalhes como a hiperglicemia, que é um

Tabela 2. Manejo do pé diabético infectado.

\begin{tabular}{|c|c|c|c|c|}
\hline Infecção & Clínica & Tratamento & Germe & Observação \\
\hline Leve & $\begin{array}{l}\text { Úlcera rasa; } \\
\text { menos de } 2 \mathrm{~cm} \text { de celulite; } \\
\text { sem fasceíte, abscesso ou } \\
\text { osteomielite; } \\
\text { sem isquemia; } \\
\text { bom controle glicêmico }\end{array}$ & $\begin{array}{l}\text { 1. Cefalosporina } 1^{a} \text { geração; ou } \\
\text { 2. Clindamicina } 300 \mathrm{mg} \text { VO q6h; ou } \\
\text { 3. Amoxicilina/clavulanato } 500 \mathrm{mg} \text { VO q8h ou } \\
875 \mathrm{mg} \text { VO q12h. }\end{array}$ & $\begin{array}{l}\text { CGP } \\
\text { Staphylococ- } \\
\text { cus aureus e } \\
\text { Streptococci }\end{array}$ & $\begin{array}{l}\text { ATB VO ambu- } \\
\text { latorial } \\
\text { (geralmente } \\
\text { por } 2 \text { semanas) } \\
\text { Cuidados } \\
\text { locais }\end{array}$ \\
\hline $\begin{array}{l}\text { Potencial- } \\
\text { mente fatal } \\
\text { ou mutilante } \\
\text { (amputação) }\end{array}$ & $\begin{array}{l}\text { Úlcera profunda; } \\
\text { mais de } 2 \mathrm{~cm} \text { de celulite; } \\
\text { suspeita de infecção pro- } \\
\text { funda; } \\
\text { isquemia; } \\
\text { mau controle glicêmico }\end{array}$ & $\begin{array}{l}\text { 1. Clindamicina, } 600 \mathrm{mg} \text { EV q8h + FQ ou } \\
\text { Cefalosporina de terceira geração; ou } \\
\text { 2. b-lactâmico + inibidor de b-lactamase } \\
\text { (Ampicilina/sulbactam; Amoxicilina/clavulana- } \\
\text { to; Piperacilina/ tazobactam); ou } \\
\text { 3. Vancomicina + Iminepen/ cilastatina (reser- } \\
\text { vado para infecções que ameaçam a vida do } \\
\text { paciente). }\end{array}$ & $\begin{array}{l}\text { Polimicro- } \\
\text { biana: CGP } \\
\text { Anaeróbios } \\
\text { (Bacteroides } \\
\text { fragilis) e } \\
\text { BGN (E. coli) }\end{array}$ & $\begin{array}{l}\text { Tratamento } \\
\text { hospitalar } \\
\text { (tempo variá- } \\
\text { vel) } \\
\text { Avaliação } \\
\text { cirúrgica espe- } \\
\text { cializada }\end{array}$ \\
\hline
\end{tabular}

ATB: antibióticos; BGN: bacilos Gram-negativos; CGP: cocos Gram-positivos; EV: endovenoso; FQ: fluoroquinolonas; VO: via oral. 
sinal comum, e não apenas aos sinais clássicos (secreção purulenta, crepitação, sinais inflamatórios e flogísticos).

É mandatório que todo paciente tenha extremo cuidado com seus pés e seja submetido a avaliação anual da sensibilidade com monofilamento de nylon de 10 gramas - conforme o consenso da Sociedade Brasileira de Diabetes para detecção e tratamento das complicações crônicas do DM (40) -, ou de número 5.07 - de acordo com Caputo e cols. (41) em artigo de revisão sobre o assunto.

Ainda em relação aos quadros infecciosos é preciso ter sempre em mente a possibilidade da presença de osteomielite. Este diagnóstico, entretanto, é sempre um desafio, sendo fundamental associar a avaliação clínica com métodos de imagem. $\mathrm{Na}$ análise clínica, pode ser de grande utilidade o simples exame da região ulcerada com uma pinça estéril de ponta romba. $\mathrm{O}$ valor preditivo positivo para osteomielite parece ser alto se for possível tocar estruturas ósseas, mas a impossibilidade não permite afastar a existência desta infecção $(42,43)$. A presença da deformidade tipo "dedo em salsicha" com ulceração adjacente parece ser fortemente indicativa de osteomielite (44).

As provas de atividade inflamatória como velocidade de hemossedimentação (VHS) e proteína C-reativa complementam a avaliação clínica, mas têm baixa sensibilidade. Uma VHS bastante elevada, aproximando-se de $100 \mathrm{~mm}$ na primeira hora, associada a úlcera em pé diabético é altamente sugestiva de osteomielite subjacente (45).

Com relação aos métodos de imagem, alguns dados devem ser considerados. Nos casos de osteomielite, os sinais radiológicos levam em média 2 semanas para se tornar evidentes (sensibilidade de 60\%). A existência de osteoartropatia de Charcot pode levar a falso-positivos no exame radiológico simples. Cintilografia (3 fases com Tecnécio e leucócitos marcados) e ressonância nuclear magnética são exames com alta sensibilidade (acima de $85 \%$, aparentemente equivalentes), porém de alto custo e com baixa especificidade (46).

Um interessante e polêmico estudo publicado por Eckman e cols. sugere que para pacientes com DM tipo 2, na suspeita de osteomielite, exames não invasivos são caros e podem não trazer maior benefício ao tratamento, quando comparados com antibioticoterapia empírica (antibioticoterapia oral por 10 semanas, baseado em antibiograma, depois de adequado debridamento e avaliação vascular) (47). Esse estudo também nos lembra de que, mesmo nos casos bem manejados, a osteomielite em pé diabético dificilmente tem índices de cura maiores que $80 \%$.
Nos casos de osteomielite, o melhor preditor de um bom prognóstico é a ausência de necrose, gangrena e edema. Também parece que tempo de DM, hipertensão, febre, tabagismo e história de amputações prévias não estão associados com o prognóstico (48).

Os cuidados locais necessários no tratamento do pé diabético incluem o debridamento de áreas desvitalizadas e calos, realização de curativos estéreis e alívio da pressão sobre áreas ulceradas. O debridamento inicial deve ser realizado independente das condições de perfusão local sempre que houver envolvimento do tecido celular subcutâneo, necrose ou drenagem purulenta, deixando-se qualquer plano de revascularização para um segundo tempo (após tratamento de eventual sepse).

Além dos microorganismos citados na tabela 2, vários outros podem estar envolvidos nas infecções do pé diabético. Os germes anaeróbios só receberam maior atenção nos últimos anos $(49,50)$. Mais recentemente, tem sido preocupante o aumento do número de casos de infecções por patógenos multirresistentes, destacando-se dois grupos:

Bacilos Gram-negativos (BGN) produtores de beta-lactamases cromossômico-induzíveis. Os gêneros mais importantes deste grupo são Enterobacter, Serratia, Providencia, Citrobacter e Morganella. Mesmo quando o antibiograma aponta sensibilidade às cefalosporinas de terceira geração, dá-se preferência ao uso das de quarta geração por induzirem à resistência em menor proporção. Fluoroquinolonas, aminoglicosídeos e carbapenêmicos podem ser também utilizados, dependendo do antibiograma e da gravidade do caso (51).

BGN produtores de beta-lactamase de espectro ampliado (ESBL). Destacam-se a E. coli e a Klebsiella pneumoniae. Deve-se suspeitar de infecção por germes produtores de ESBL quando o antibiograma acusa sensibilidade às cefamicinas (cefoxitina) e resistência às cefalosporinas de terceira geração - em especial à ceftazidima - e ao aztreonam. Deve ser realizada confirmação através de testes mais específicos, como o E-test. Os carbapenêmicos são os antibióticos de escolha $(51,52)$.

\section{OUTRAS CONSIDERAÇÕES}

Com relação à interação entre DM e a terapia com antimicrobianos, devem-se fazer algumas considerações. As sulfonamidas e o cloranfenicol podem potencializar os efeitos hipoglicemiantes das sulfoniluréias de primeira geração. Outro fato muitas vezes esquecido é que muitos antibióticos são diluídos em soluções com grande carga de glicose. Além disso, pacientes com DM têm a absorção intramuscular 
diminuída (53). Certos antimicrobianos (cefalosporinas, cloranfenicol, ácido nalidíxico, isoniazida, nitrofurantoína, tetraciclina e penicilina) podem induzir resultados falso-positivos em determinados tipos de testes de glicosúria (53).

No que diz respeito às drogas usadas para o tratamento de infecções no pé diabético, deve-se descartar a cefoxitina devido ao seu alto poder de induzir a produção de beta-lactamase. Como novidade, o uso dos fatores estimulantes de colônias de granulócitos (G-CSF) parece promissor. Gough e cols. (54) apresentaram o uso de G-CSF diminuindo o tempo de antibioticoterapia, o número de internamentos e o tempo de evolução da doença, resultado atribuível a uma melhor síntese de radicais superóxido pelos neutrófilos. Seu uso ainda é experimental.

DM também parece ser fator predisponente para outras infecções, como salmonelose (55). De acordo com um estudo não publicado apresentado por Aleksic-Djordjevic e cols. no 9th International Congress of Infectious Diseases (56), talvez seja uma condição não infecciosa predisponente à meningite bacteriana comunitária.

É imprescindível destacar a importância da experiência clínica, da prevenção, do diagnóstico precoce e do acompanhamento multidisciplinar para a obtenção dos melhores resultados durante o tratamento das infecções em pacientes diabéticos.

\section{REFERÊNCIAS}

1. Malerbi DA, Franco LJ. Multicenter study of the prevalence of diabetes mellitus and impaired glucose tolerance in the urban Brazilian population aged 30-69 yr. The Brazilian Cooperative Group on the Study of Diabetes Prevalence. Diabetes Care 1992; 15:1509-16.

2. Joshi N, Caputo GM, Weitekamp MR, Karchemer AW. Infections in patients with diabetes mellitus. N Engl J Med 1999:341;1906-12.

3. Wheat LJ. Infection and diabetes mellitus. Diabetes Care 1980;3:187-97.

4. Delamaire M, Maugendre D, Moreno M, Le Goff MC, Allannic H, Genetet B. Impaired leucocyte functions in diabetic patients. Diabet Med 1997; 14:29-34.

5. Gallacher SJ, Thomson G, Fraser WD, Fisher BM, Gemmell CG, MacCuish AC. Neutrophil bactericidal function in diabetes mellitus: evidence for association with blood glucose control. Diabet Med 1995; 12:916-20.

6. de Marie S. Diseases and drug-related interventions affecting host defence. Eur J Clin Microbiol Infect Dis 1993; 12(Suppl 1):S36.

7. McMahon MM, Bistrian BR. Host defenses and susceptibility to infection in patients with diabetes mellitus. Infect Dis Clin North Am 1995;9:1-9.
8. Fine MJ, Smith MA, Carson CA, Mutha SS, Sankey SS, Weissfeld LA, et al. Prognosis and outcomes of patients with community-acquired pneumonia: a meta-analysis. JAMA 1996;275:134-41.

9. Banyai AL. Diabetes and pulmonary tuberculosis. Am Rev Tuberc 1931;24:650-67.

10. American College of Physicians Task Force on Adult Immunization. Guide for adult immunization. $2^{\text {nd }}$ ed. Philadelphia: American College of Physicians, 1990.

11. Koziel H, Koziel MJ. Pulmonary complications of diabetes mellitus - pneumonia. Inf Dis Clin N Amer 1995;9:65-96.

12. Geerlings SE, Stolk RP, Camps MJ, Netten PM, Hoekstra $\mathrm{JB}$, Bouter KP, et al. Asymptomatic bacteriuria may be considered a complication in women with diabetes. Diabetes Mellitus Women Asymptomatic Bacteriuria Utrecht Study Group. Diabetes Care 2000;23:744-9.

13. Patterson JE, Andriole VT. Bacterial urinary tract infections in diabetes. Inf Dis Clin N Amer 1997; 11:735-50.

14. Zhanel GG, Harding GKM, Nicolle LE. Asymptomatic bacteriuria in patients with diabetes mellitus. Rev Infec Dis 1991;13:150-4.

15. Vejlsgaard R. Studies on urinary tract infection in diabetes. I. Bacteriuria in patients with diabetes mellitus and in control subjects. Acta Med Scand 1966;179:173-82.

16. Pometta D, Rees SB, Younger D, Kass EH. Asymptomatic bacteriuria in diabetes mellitus. $\mathbf{N}$ Engl $\mathbf{J}$ Med 1967;276:1118-21.

17. Patterson JE, Andriole VT. Bacterial urinary tract infections in diabetes. Inf Dis Clin N Amer 1995;9:25-51.

18. Zhanel GG, Harding GKM, Guay DRP. Asymptomatic bacteriuria: which patients should be treated? Arch Int Med 1990; 150:1389-96.

19. Hooton TM, Scholes D, Stapleton A, Roberts PL, Winter C, Gupta K, et al. A prospective study of asymptomatic bacteriuria in sexually active young women. $\mathbf{N}$ Engl $\mathbf{J}$ Med 2000;343:992-7.

20. Geerlings SE, Stolk RP, Camps MJ, Netten PM, Collet TJ, Hoepelman Al. Risk factors for symptomatic urinary tract infection in women with diabetes. Diabetes Care 2000;23:1737-41.

21. Edelstein H, McCabe RE. Perinephric abscess: modern diagnosis and treatment in 47 cases. Medicine (Baltimore) $1988 ; 67: 118-31$.

22. Mangan D, Selwitz RH, Genco R. Infections associated with diabetes mellitus. N Engl J Med 2000;342:896.

23. Collin HL, Uusitupa M, Niskanen L, Kontturi-Närhi $V$, Markkanen $\mathrm{H}$, Koivisto AM, et al. Periodontal findings in elderly patients with non-insulin dependent diabetes mellitus. J Periodontol 1998;69:962-6.

24. Oliver RC, Tervonen T. Diabetes - a risk factor for periodontitis in adults? J Periodontol 1994;65(5 Suppl):530-8.

25. Taylor GW, Burt BA, Becker MP, Genco RJ, Shlossman M, Knowler WC, et al. Severe periodontitis and risk for poor glycemic control in patients with non-insulin-dependent diabetes mellitus. J Periodontol 1996;67:1085-93.

26. Sinert R, Adamson O, Johnson E, Tran D, Silverberg M. The incidence of previously undiagnosed diabetes mellitus in patients with soft tissue infections. Acad Emerg Med 2001;8:538. 
27. Green RJ, Dafoe DC, Raffin TA. Necrotizing fasciitis. Chest 1996; 1 10:219-29.

28. Sentochnik DE. Deep soft-tissue infections in diabetic patients. Inf Dis Clin N Amer 1995;9:53-64.

29. Patel SR, Olenginski TP, Perruquet JL, Harrington TM. Pyomyositis: clinical features and predisposing conditions. J Rheumatol 1997;24:1734-8.

30. Swartz MN. Myositis. In: Mandell GL, Bennet JE, Dolin R, eds. Principles and practice of infectious disease. Philadelphia:Churchill Livingstone, 2000;354-6.

31. Slattery WH III, Brackmann DE. Skull base osteomyelitis: malignant external otitis. Otolaryngol Clin North Am 1996;29:795-806. Med Sci 1961;241:604-12.

32. Rubin J, Yu VL. Malignant external otitis: insights into pathogenesis, clinical manifestations, diagnosis, and therapy. Am J Med 1988;85:391.

33. Rene R, Mas A, Villabona CM, Ricart MC, Bassa A, Tolosa F. Otitis externa maligna and cranial neuropathy. Neurologia 1990;5:222-7.

34. Bath AP, Rowe JR, Innes AJ. Malignant otitis externa with optic neuritis. J Laryngol Otol 1998; 112:274-7.

35. Tierney MR, Baker AS. Infections of the head and neck in diabetes mellitus. Infect Dis Clin North Am 1995:9:195216.

36. Yohai RA, Bullock JD, Aziz AA, Markert RJ. Survival factors in rhino-orbital-cerebral mucormycosis. Surv Ohthalmol 1994;39:3.

37. Smitherman KO, Peacock JE Jr. Infectious emergencies in patients with diabetes mellitus. Med Clin North Am 1995;79:53-77.

38. Spilchler ERS, Spichler D, Martins CSF, et al. Diabetic lower extremities amputations - Rio de Janeiro, BR. Diabetologia 1998:41(A 279):90-6.

39. Pedrosa HC. Pé diabético: aspectos fisiopatológicos, tratamento e prevenção. Rev Bras Neurol Psiquiat $1997 ; 1: 131-5$.

40. Gross JL. Detecção e tratamento das complicações crônicas do diabete melito. Consenso Brasileiro. Arq Bras Endocrinol Metab 1999:43:7-14.

41. Caputo GM, Cavanagh PR, Ulbrecht JS, Gibbons GW, Karchmer AW. Assessment and management of foot disease in patients with diabetes. N Engl J Med 1994;331:854-60.

42. Grayson ML, Gibbons GW, Balogh K, Levin E, Karchmer AW. Probing to bone in infected pedal ulcers. A clinical sign of underlying osteomyelitis in diabetic patients. JAMA 1995;273:721-3.

43. Caputo GM, Joshi N, Weitekamp MR. Foot infections in patients with diabetes. Am Fam Physician 1997:56:195202.

44. Rajbhandari SM, Sutton M, Davies C, Tesfaye S, Ward JD. 'Sausage toe': a reliable sign of underlying osteomyelitis. Diabet Med 2000; 17:74-7.
45. Newman LG, Waller J, Palestro CJ, Schwartz M, Klein MJ, Hermann $G$, et al. Unsuspected osteomyelitis in diabetic foot ulcers. Diagnosis and monitoring by leukocyte scanning with indium In-111 oxyquinoline. JAMA 1991;266:1246-51.

46. Morrison WB, Schweitzer ME, Wapner KL, Hecht PJ, Gannon FH, Behm WR. Osteomyelitis in feet of diabetics: clinical accuracy, surgical utility, and cost-effectiveness of MR imaging. Radiology 1995; 196:557-64.

47. Eckman MH, Greenfield S, Mackey WC, Wong JB, Kaplan S, Sullivan L, et al. Foot infections in diabetic patients: decision and cost-effectiveness analyses. JAMA 1995:273:712-20.

48. Bamberger DM, Daus GP, Gerding DN. Osteomyelitis in the feet of diabetic patients. Am J Med 1987;83:653-60.

49. Gerding DM. Foot infection in diabetic patient: role of anaerobes. Clin Infec Dis 1995;20:5283.

50. Wheat LJ, Allen SD, Henry M, Kernek CB, Siders JA, Kuebler T, et al. Diabetic foot infections. Bacteriologic analysis. Arch Intern Med 1986; 146:1935-40.

51. Tenover FC, Mohammed MJ, Gorton TS, Dembek ZF. Detection and reporting of organisms producing extended-spectrum beta-lactamases: survey of laboratories in Connecticut. J Clin Microbiol 1999;37:4065-70.

52. Hadziyannis $E$, Tuohy $M$, Thomas $L$, Procop GW, Washington JA, Hall GS. Screening and confirmatory testing for extended spectrum beta-lactamases (ESBL) in Escherichia coli, Klebsiella pneumoniae, and Klebsiella oxytoca clinical isolates. Diagn Microbiol Infect Dis 2000;36:113-7.

53. Moellering RC Jr. Principles of anti-infective therapy. In: Mandell GL, Bennett JE, Dolin R, eds. Principles and practice of infectious disease. Philadelphia:Churchill Livingstone, 2000:223-7.

54. Gough A, Clapperton M, Rolando N, Foster AV, PhilpottHoward J, Edmonds ME. Randomised placebo-controlled trial of granulocyte-colony stimulating factor in diabetic foot infection. Lancet 1997;350:855-9.

55. Yang $\mathrm{CH}$, Tseng $\mathrm{HH}$, Chen KJ, Liu JD. Salmonella infections: a retrospective 10-year analysis of 134 cases in a regional hospital in Taiwan. Scand J Infect Dis 1996;28:171-5.

56. Aleksic-Djordjevic M, Vukadinov J, Samardzija N, Canak $G$, Turkulov $V$. Non-infectious predisposing factors in adult patients with bacterial meningitis. 9th International Congress of Infectious Diseases. 2000;95:221(abstract 066).

\section{Endereço para correspondência:}

Jaime Luís Lopes Rocha

Av. Iguaçu, 3001 ap. 2204

80240-031 Curitiba, PR

e.mail: jaimeluis@b.com.br 